Pearce, Thomas. "'...So it really is a series of tubes.' Google's Data Centers, Noo-politics and the Architecture of Hegemony in Cyberspace " Enquiry 10.1 (2013) 43-53.

\section{"...So it really is a series of tubes." Google's Data Centers, Noo-politics and the Architecture of Hegemony in Cyberspace}

Thomas Pearce

\section{ABSTRACT}

In recent years, the physical manifestation and infrastructure of the informational age has increasingly drawn the attention both of the popular imagination and of architectural theorists. This paper focuses on an aspect mostly overlooked to date, namely on its artistic representation. It provides a critical analysis of a series of data center photographs published by Google in October 2012 under the name "Where the internet lives". The photographs are examined as carefully staged constructions of a specific imagination of information technology that, transcending a purely aesthetical or corporate critique, has broad political, sociogeographical and economical implications. A first analysis of their composition, digital manipulation and visual impact situates the images within a recent photographic current of the so called "anthropogenic Sublime". The paper then zooms out to reframe the photographs as a continuation of the euphoric techno-utopian discourse that surrounded the popular dissemination of the internet in the early nineteen-nineties. This discourse hailed the internet as an inherently moral and emancipatory vehicle that, because of the non-physical nature of cyberspace, would liberate its users from traditional hegemonic dispositifs based on techniques of physical coercion. Tracing the transition from bio-political (Foucault) to noo-political dispositifs (Lazarrato, Deleuze) and discussing the inextricable connection between information technology, territorial conflict and socio-geographic inequality, the article goes on to account for the demise of the dream of a "bodiless and moral internet". Finally, the data center images are re-read in more detail and discussed as part of the life-support system of a failed utopia - sustaining a popular yet reductionist understanding of the informational society and its key players.

KEYWORDS: civilian-military-industrial complex, cybernetics, cyberspace, data centers, hegemony, infrastructure, internet, noopolitics, photography, sustainability
"You walk through those doors and the world opens up to you. It's a culture where information is free. A culture where the more you share and the more you ask the more you get."'

"This is the beating heart of the digital age - a physical location where the scope, grandeur, and geekiness of the kingdom of bits become manifest."

"As we leave the floor, I feel almost levitated by my peek inside Google's inner sanctum." 2

"Google, I really love you. If you were a person I would leave my wife and marry you :)_"

"no Google , no protection!"

"Beautiful. Clean and organized but with Google you would expect nothing less."

"This is corporate propaganda that truly is a treat for the eyes"4

"...So it really is a series of tubes."

(Some reactions to the data center images)

\section{Transparency}

On the 17th of October 2012, the world was in awe as Google went transparent. On a website called "Where the internet lives", Google released a series of over 80 images by photographer Connie Zhou, offering the first ever glimpse into their top-secret data centers. ${ }^{6}$

Up to that point, the Google data centers, accommodating the search engine's ever growing number of servers, had been clouded in secrecy. An article, published earlier that year in Wired Magazine, described how, "paranoid about the competitors catching a glimpse of its gear", Google let the maintenance staff of an outsourced server farm work in complete darkness, only allowing the use of miner's headlamps. ${ }^{7}$

In their own data centers, the company developed the most advanced customized server hardware, including highly efficient techniques for the demanding task of cooling its servers. Once disclosed, as critics like Greenpeace argued, these techniques could also help to sink the carbon footprint of other companies and thus enhance the sustainability of the entire sector. Facebook, one of the advocates of sharing know- 


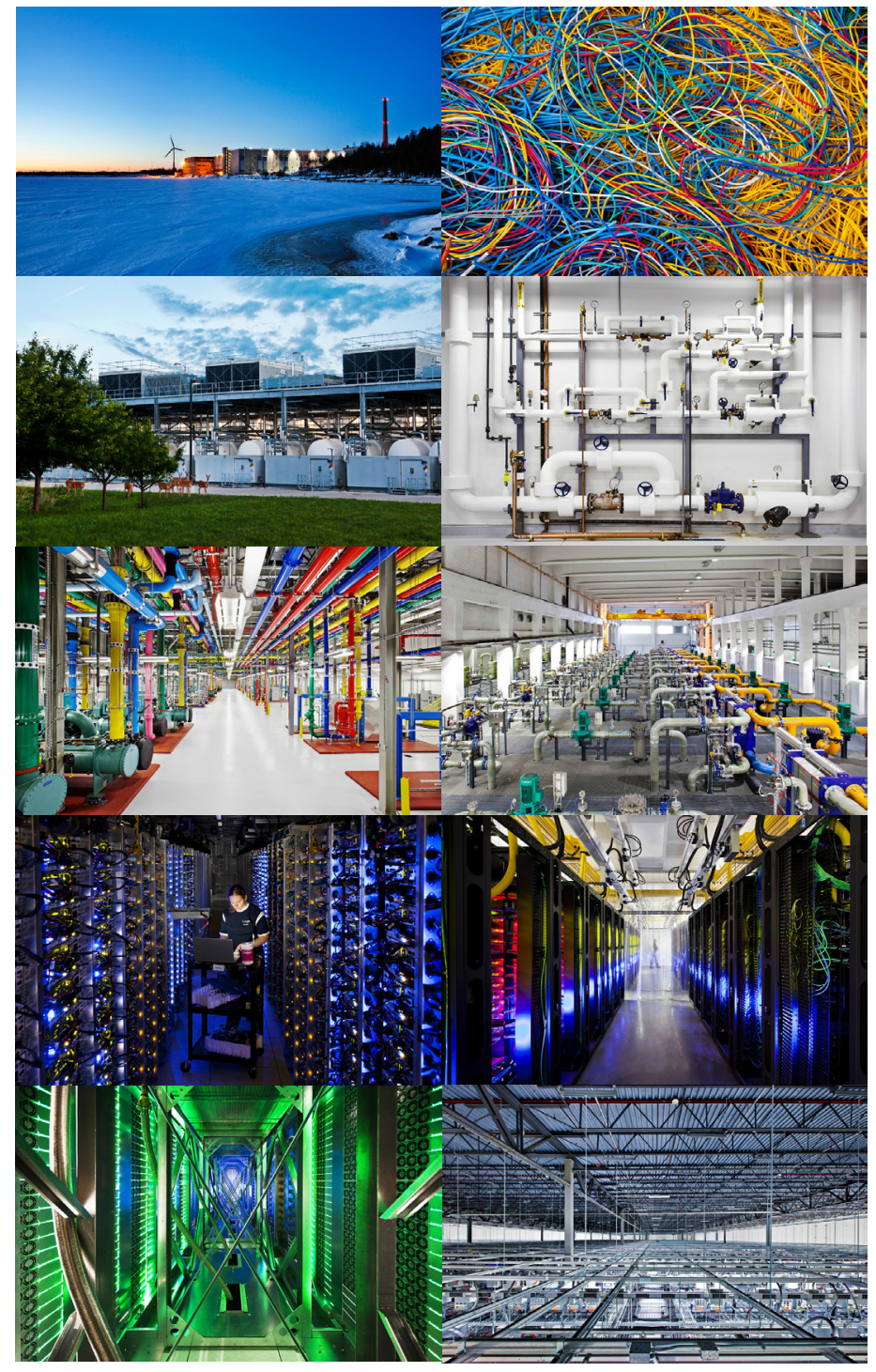

Figure 1: "Where the internet lives", Photographer: Connie Zhou

how had made a point of publishing its data and allowing journalists and architectural photographers into their own data centers. ${ }^{8}$

Then Google struck back, and its strategy was sophisticated: by not just allowing a newspaper photographer to visit their facilities for a day but instead hiring an architectural photographer, who spent multiple weeks exploring and photographing ${ }^{9}$, Google proved that its data centers were not only transparent, but above all, that they were beautiful.

\section{The Anthropogenic Sublime}

Even when refraining from the quasi-religious enthusiasm of the quotes opening this article, it is hard to deny that the photographs have a certain awe-inspiring quality. Presenting a highly aestheticizing gaze on the man-made environment, the images have a certain kinship to the work of photographers like Andreas Gursky, Edward Burtynsky or Bas Princen, who operate within a recent tradition of what could be called the "anthropogenic Sublime". The Sublime was originally described by Edmund Burke in APhilosophical Enquiry into the Origin of Our Ideas of the Sublime and Beautiful (1756) as "whatever is fitted in any sort to excite the ideas of pain and danger... Whatever is in any sort terrible, or is conversant about terrible objects, or operates in a manner analogous to terror". ${ }^{10}$

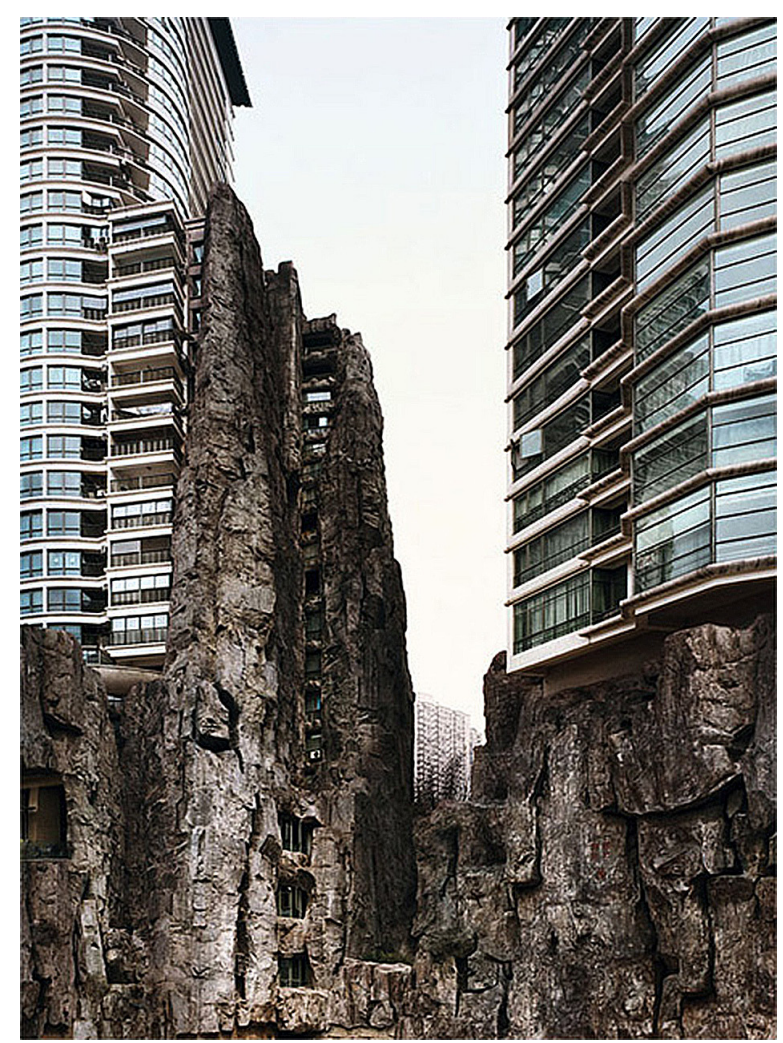

Figure 2: Bas Princen, Valley (China), 2008

Whereas for Burke the Sublime was to be found in the vastness of nature and the inevitability of the Divine, for the photographers in question the natural landscape of the romantic tradition - in its entirety cultivated and exploited, known and broadcasted - has lost its aura of mystery and danger. Instead, the infrastructural, (post)industrial, and urban landscape has become the source of the Sublime. The dual emotion of danger and attraction is now invoked by the "vertiginous dynamic of globalization", a globalization that arguably has become our new "Divine". ${ }^{11}$

Let us take as an example the series of photographs of stock exchanges from around the world that Gursky produced in the late nineties. The images show, from a bird's eye perspective, vast and colorful seas of 
people, paper and screens. The depth of field stretches the entire image, showing every element in crisp detail. Gursky thereby refuses to establish hierarchy, bathing the image in an extensive sameness that does not seem to be confined by its frame but extends far beyond and deep into our own existence. It is the vastness and abstraction of man-made global capitalism gone out of control that is at once disturbing and aesthetic and thus serves as the source of the Sublime. In these photographs, man himself becomes the "man-made" landscape. completely mirrored around their central axes. Blogs and newspapers, which just previously had published the images and had shared in the excitement surrounding them, felt deceived and published illustrated analyses of the manipulations. ${ }^{13}$

Google was fast to react and in turn released some before-after images and an interview with the photographer:

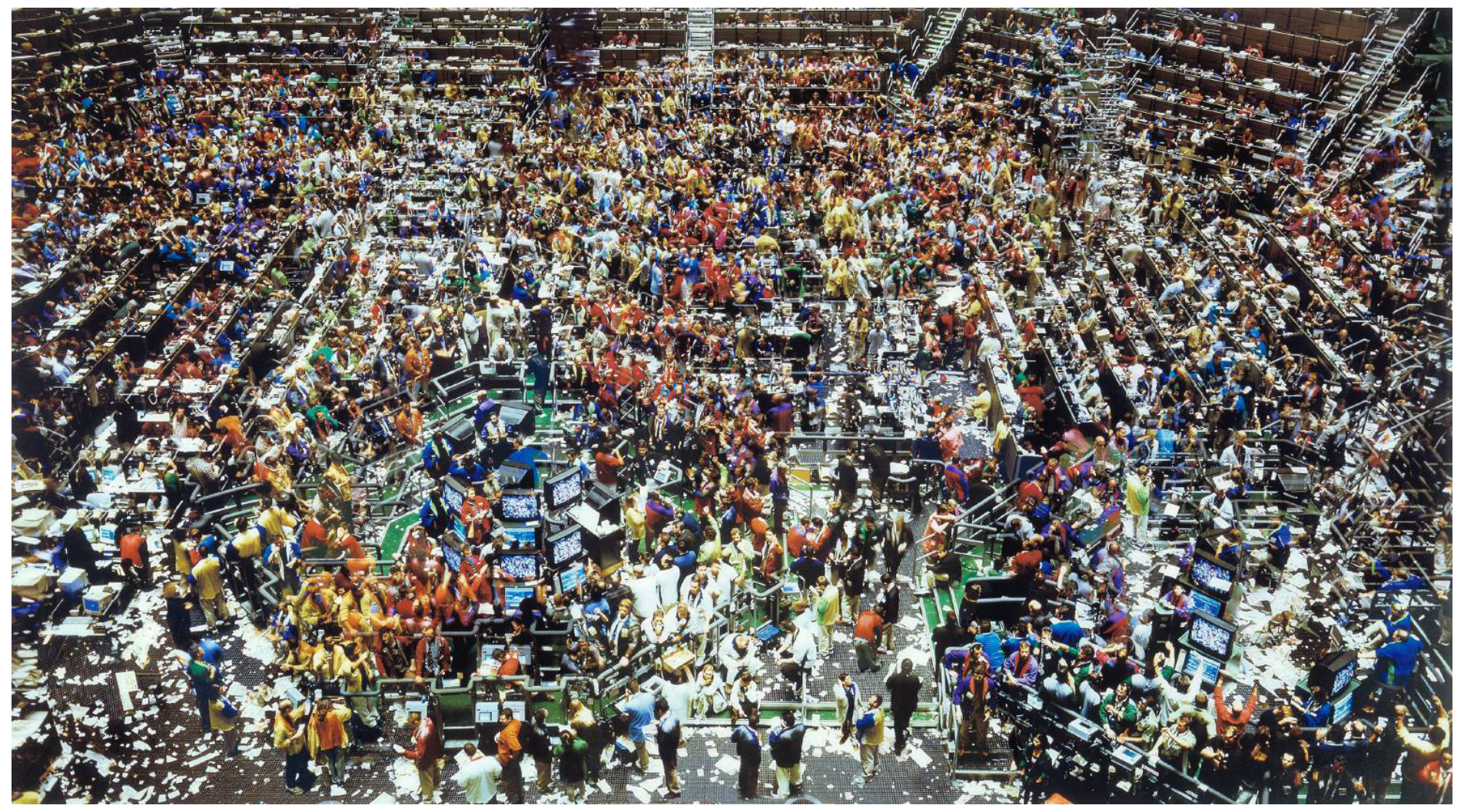

Figure 3: Andreas Gursky, Chicago Board of Trade II, 1999

Interestingly, Gursky has often been compared to the painter Caspar David Friedrich, the master of the romantic Sublime. Gursky, in turn, regards the distinction between the painter and the photographer as outdated, seeing both as producers of "images" in a broad sense of the word. ${ }^{12}$ Any Photoshop user will confirm how similar the process of digital post-production - with its brushes, stamps and sponges - is to the process of painting. Like a painter, the photographer can manipulate that which is depicted and thereby amplify (his understanding of) the truth.

Soon after Google's data center photographs were published, critical observers started noticing and blogging about the fact that they too were heavily manipulated. In the most blatant cases, the images were
"Beauty is something with a lot of symmetry. It's more about the lines of everything I photograph [...] My goal was to help people see the beauty of the data centers. I had a certain artistic license to interpret the scene, but Google didn't want me to hide or obscure anything - any changes I made to a scene were aesthetic." 14

It is not my intention here to do the work of Photoshop forensics and uncover that the images are manipulated. Nor do I want to engage in the discussion on whether it is correct to use artistic license to manipulate these images. Rather, I want to concentrate here on the question what kind of image is constructed through manipulation and how techniques of manipulation and composition contribute to this constructed reality. 
Because, in spite of the artist's statement, composition is not just a matter of aesthetics.

\section{Soothing Symmetry}

Symmetric composition, for example, is much more than an aesthetic choice. The construction of many of the data center images is based on central perspective (achieved sometimes, but not exclusively, through mirroring). Describing an example of renaissance central perspective, Marshall McLuhan dramatically states:

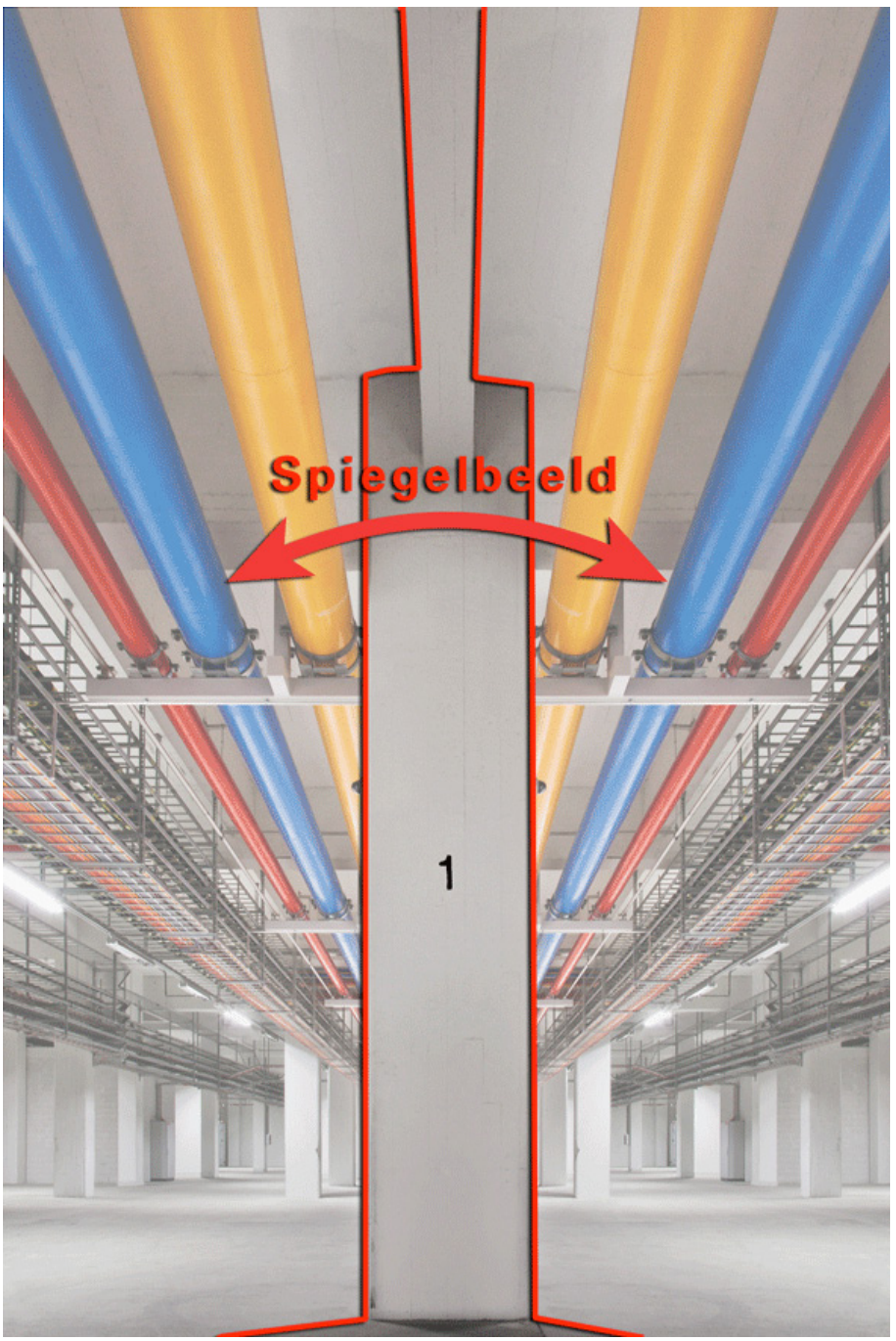

Figure 4: Manipulation Analysis, Nieuwe Rotterdamse Courant

"The Vanishing Point = Self-Effacement // The Detached Observer. No Involvement! The Viewer of Renaissance art is systematically placed outside the frame of experience. "
He goes on to state:

"The instantaneous world of electric informational media involves all of us, all at once. No detachment or frame is possible."15

Following McLuhan's argument, the data center images thus try to achieve the impossible: to depict the "instantaneous world of electric informational media" (the "internet" didn't exist at the time of writing) as a framed, thus controlled and externalized central perspective. The human, the viewer, is placed outside of the framed image. In the few

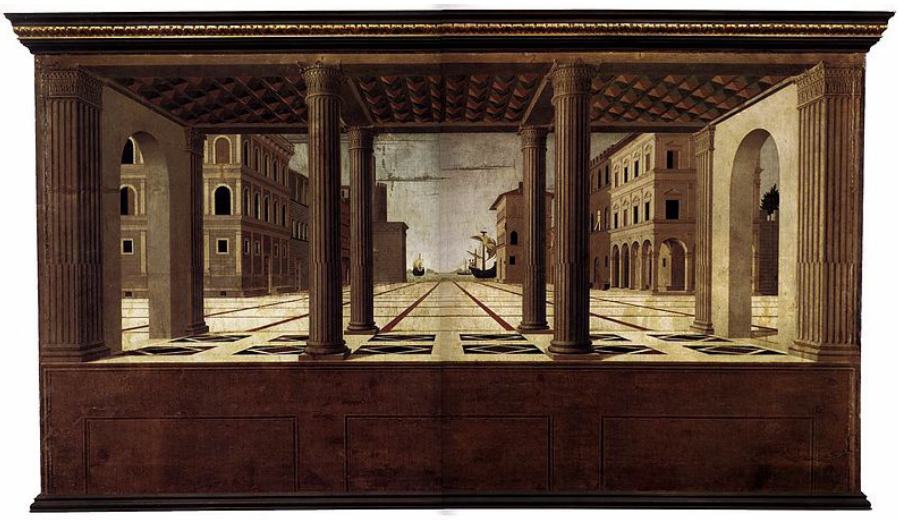

Figure 5: Fransesco di Giorgio, Ideal City, 1477

cases where a human appears in the data center images, he is neatly arranged to coincide with the central perspective's vanishing point. Surrounding him, the server racks, made for the human scale, are well labeled and securely kept, like the shelves of a library. All is within reach of the vitruvian maintainer.

If Gursky's manipulations create disturbing flatness and vastness defying the rules of perspective and control, the data center images attempt quite the opposite. Their soothing symmetry seems to suggest to us that we need not worry, that those in charge have everything under control. In other words, if Gursky's images seem to echo the logic of extensionism and second-class cybernetics - in which the observer himself is understood as an intrinsic part of the system he observes - the data center images speak the language of first-class cybernetics - of the subject, the engineer in charge. ${ }^{16}$

These observations start to suggest that there is more at stake here than the critique of aesthetics or of corporate propaganda. Indeed, the photographs are revealing with regard to our perception of "the" Internet. At this point it is important to emphasize that the identification of Google (or its data centers) with the Internet, as suggested by the title of the photographic essay "Where the Internet lives", shouldn't be accepted without further reflection. Google is a multinational organization known mainly for its search engine - it searches the internet without being it. 
However, as the verb "to google" is being included in most dictionaries and the "ungoogleable" increasingly becomes the limit of our epistemic horizon, it is fair to say that in public perception, Google is increasingly identified, as a pars pro toto, with the Internet. Therefore, a study of the Google data centre images can indeed lead us to broader conclusions regarding the production of an image of the Internet.

Let us now take one step further back and ask ourselves: by whom and for whom are these mental constructs produced (i.e. not just the

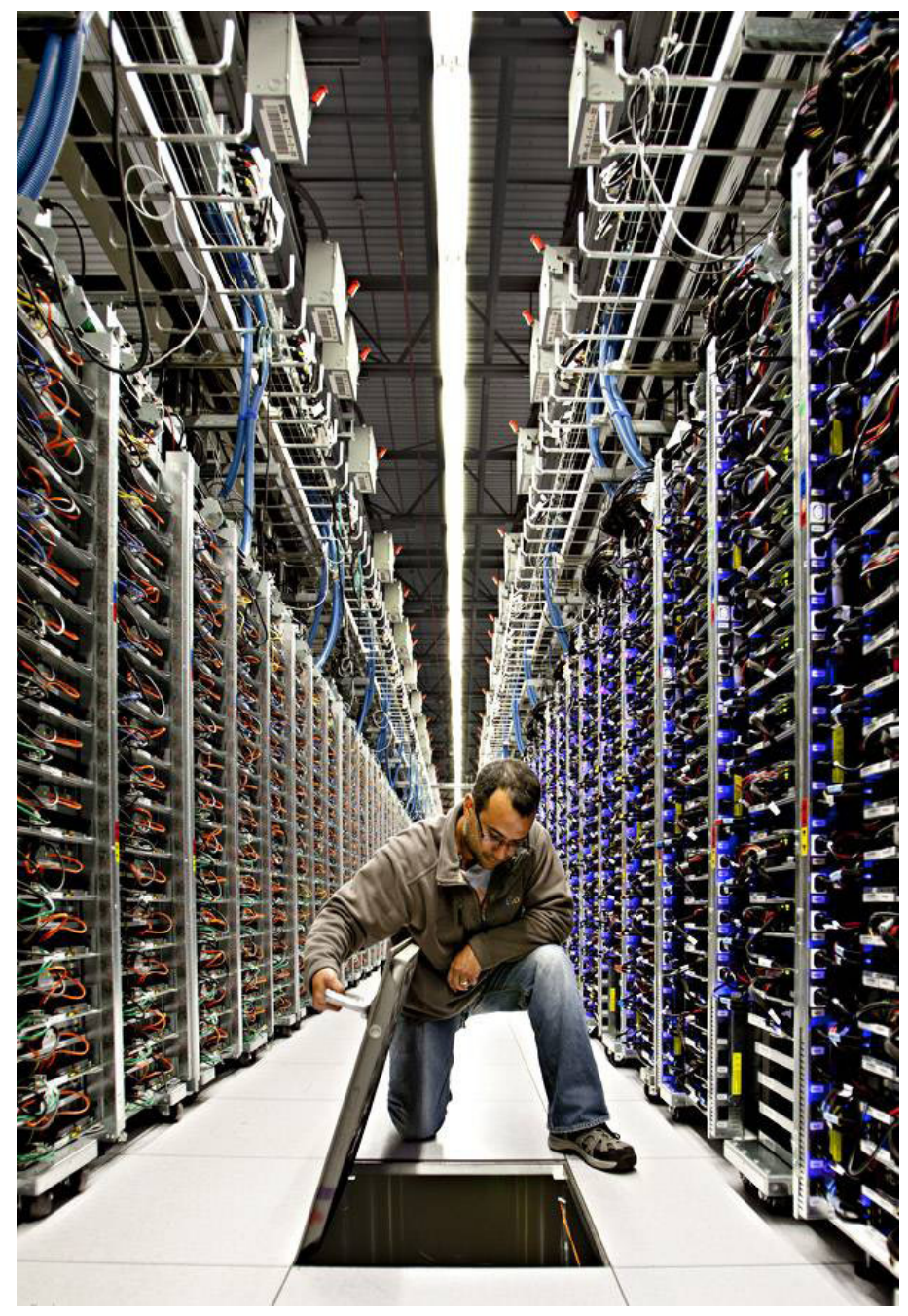

Figure 6: "Where the internet lives", Photographer: Connie Zhou

photographs in question but the understanding of technology and the Internet that they conjure up)? Whose purposes and benefits do they serve? And maybe also: what don't they show? For when examined in the broader context of its production, every image can shed light on those power relations, whether they be political, social, geographical, or financial, that originally underlay it - relations that would be obfuscated by studying it solely as a "work of art". ${ }^{17}$

\section{The Utopia of a Bodiless and Moral Internet "Code is the architecture of the 90's" (Douglas Coupland, Microserfs) ${ }^{18}$}

The image of the Internet constructed through the data center photographs has its origin in the utopian ideals that surrounded the advent of the internet in the 1990s. At this point, therefore, a brief digression into this history is apposite.

The hope that the Internet could be a liberating and emancipatory force is nowhere as clearly expressed as in John Perry Barlow's 1996 "Declaration of the Independence of Cyberspace":

"Governments of the Industrial World, you weary giants of flesh and steel, I come from Cyberspace, the new home of Mind. On behalf of the future, I ask you of the past to leave us alone. You are not welcome among us. You have no sovereignty where we gather."

Against the old, physical world of "flesh and steel", he puts the bodiless world of the Internet:

"Cyberspace consists of transactions, relationships, and thought itself, arrayed like a standing wave in the web of our communications. Ours is a world that is both everywhere and nowhere, but it is not where bodies live."

Consequently, freed of the inherited power relations of matter, the Internet is hailed as an emancipatory tool:

"Your legal concepts of property, expression, identity, movement, and context do not apply to us. They are all based on matter, and there is no matter here. [...] Our identities have no bodies, so, unlike you, we cannot obtain order by physical coercion." 19

Interestingly enough, political forces both on the left and on the right shared this cyberspace euphoria. The Italian Autonomists, for example, celebrated the advent of the Internet because, driven by the immaterial forces of language and subjectivity, it would enable a neo-communist utopia. ${ }^{20}$

On the other side of the political spectrum, a far more influential utopian brainchild of this era was the so-called "Californian Ideology". It was a peculiar mix of the concept of bodiless and emancipatory information technology and the anti-state ideology of individualism and meritocracy. In a "post-industrial, post-capitalist, knowledge based economy, the exploitation of information and knowledge would drive growth and wealth creation while diminishing the older power structures of the state in favor of connected individuals in virtual communities." 21 
Originally the ideology of the managerial class of Silicon Valley, these ideas spread rapidly to influence the highest of American political spheres. ${ }^{22}$ Its economical translation was called the New Economy - the belief that, if only the state would keep its hand off the economy, it would function as a kind of cybernetic self-regulating system, run by computers and the logic of feedback. The optimism of New Economy famously led to the late-nineties politics of laisser-faire, deregulation and privatization.

\section{Utopia's Failure}

"We all get older and smarter", Perry Barlow observed in 2004 when evaluating his optimism of the nineties. ${ }^{23}$ Indeed, it is not an overstatement to say that the utopian hopes sparked by information technology have in large parts been disappointed. In the context of the global economy, a series of economic crises have discredited the New Economy. They proved that the politics of laisser-faire did not lead to a self-regulating system to the benefit of all but instead led to a system regulated by the interests of banks and corporations that benefited only a dwindling number of the happy few.

The internet itself doesn't seem to have fulfilled its promises either. For instance, the freedom of thought and identity praised by Barlow has made place for a commodification of subjectivity, as "multinational corporations have determined how to extract monetary value from the Internet primarily by exploiting the social life and free labor of its users." ${ }^{24}$ Should we then revise our comparison of data centers to libraries and describe them instead as banks, for which the currency is information, and which trade our personal and intimate information to data miners in transaction chains that are unintelligible to the information's actual owner; banks that pay interest only in the form of the comfort of using their services?

In addition, the revelations in the summer of 2013 of whistleblower Edward Snowden, former employee of the National Security Agency, about the extent of government spying on its own citizens through access to the servers of large tech companies like Google - the very servers depicted in the images under study - has given a definitive deathblow to the idea of the internet as inherently free. Whatever the nature of the companies' involvement in these operations might have been ${ }^{25}$, public perception of privacy and data storage has experienced a massive shift. The naively positive notion of transparency exemplified by the data centre images has backfired - revealing the citizens themselves as the ones transparent to the gaze of the government, who's own operations remain covert.

How can we explain the failure of this tech-utopia? It could be argued that its nonfulfillment is, in fact, based on the falseness of its very premises: the Internet as bodiless and the Internet as intrinsically moral. The following paragraphs will elaborate upon, and deconstruct, these two assumptions. Firstly by illustrating that the physical world refuses to die and that hegemony is still founded in "real" space, and secondly by stating that even the bodiless, virtual realm of the internet is not per se moral, not per se emancipatory and that it can eventually also be instrumentalized by techniques of hegemony and noo-politics.

\section{Place Matters}

The realization of the very existence of the data centers, banal though it may seem, is a smack in the face for the credo of the immaterial Internet. Information has refused to dematerialize. The data centers are the "places of the space of flows" that show that place does matter; that property - deemed obsolete by Barlow's Declaration - is still relevant; that owning - no matter how deterritorialized the object owned - is still performed in spatial terms.

The implications of these observations are rather far-reaching. The Internet is not only intrinsically territorial in that it is territorially owned but also because it owes its existence to territorial conflict and territorial inequality.

First of all, the development of the Internet springs from territorial conflict. Research and development in information technology were long dominated by the so-called military-industrial complex. Like other dualuse technologies, such as the Global Positioning System, the Internet is a brainchild of the cold war period - a war that, as it never "took place", was indeed less dominated by actual physical weapons than by the abstract possibility of their imminent deployment or even existence. The military-industrial complex not only produced political dominance and the feeling of safety, but also contributed to national economic growth.$^{26}$

From the seventies on, information technology was opened up for civilian use and was commercialized and privatized. In public perception, its military origin became increasingly mystified as it was transplanted from the Pentagon to the garage. Although the entrepreneurs of Silicon Valley had "merely skimmed the cream off the top"27 of military development, the Garage Myth (this late twentieth century version of the American dream) imagined them as independent, creative and individual discovers that developed their ideas in the apolitical zone of the private home.

The introduction of information technology to the larger public in fact proved so successful that it inversed the logic of the military-industrial complex. Owing to this proliferation, but also to drastic cuts in military spending following the end of the cold war, the military has become increasingly dependent on the innovation of the private sector. To take an example, the simulation software developed in Silicon Valley for use in animated Hollywood movies or in gaming technology is received with open arms by the American military. Thus, by now, the "state's monopoly over violence depends on global consumption of entertainment, communication and transportation." 28 The state now takes measures to "stimulate the creation of an integrated civilian-military industrial base."29 This alliance is characterized by public-private partnerships, like the cooperation between Google and NASA on the Gigapan project. ${ }^{30}$ When looking at Silicon Valley not as a narrative but as a geographical 
place, where military testing facilities and Facebook, Google and Lockheed Martin, NASA and IBM are close neighbors, the intertwining of private and public interests, of military and civilian goals, becomes immediately apparent.

A visit to Silicon Valley also reveals a second, very territorial, condition on which the Information Society is built: socio-geographical inequality. The growing wealth of the Valley's "digerati" is unthinkable without the backing of a much larger group of thousands of (mainly non-white) badly paid, unskilled manufacturing and assembly workers, mainly living in the South of the Valley. ${ }^{31}$ Also beyond its Californian cradle, the Information Age is characterized by "technological apartheid" and a growing gap between information haves and have-nots. ${ }^{32}$

\section{The Amoral Web and Noo-politics}

The second premise to be scrutinized here is that of information technology as per se moral and emancipatory. In his 2005 essay titled The Amorality of the Web 2.0, Nicholas Carr cynically stated it as follows: "Like it or not, Web 2.0, like Web 1.0, is amoral. It's a set of technologies [...] that alters the forms and economics of production and consumption. It doesn't care whether its consequences are good or bad. It doesn't care whether it brings us to a higher consciousness or a lower one. [...] So let's can the millenialist rhetoric and see the thing for what it is, not what we wish it would be."

Whether or not joining in Carr's defeatism, it is important to understand his distinction between technological means and ideological goals. Rather than automatically subverting or even transcending existing hegemonies, the advent of the "amoral" internet has merely extended the sphere of action of hegemonic techniques - and of their contestation. Once subjectivity has been liberated within the immaterial realm of interconnected brains, exercising power is redefined as "establishing command over subjectivity itself'. ${ }^{33}$

The definition of power as the ability to influence and construct public opinion and collective perception through telematic technologies is what Maurizio Lazzarato calls noo-politics (from the Greek noo, mind). After Foucault's bio-politics and disciplinary societies, noo-politics operate within a "society of control", in which power is no longer exercised over the class or the crowd but over the "public". It is "the public of the media, the public of a newspaper: [...] a dispersed crowd in which the influence of minds [...] on one another has become an action at a distance." ${ }^{34}$

The immaterial strategies of "modulation of the brain" do not, however, replace the material logic and techniques of physical coercion characterizing disciplinary societies (such as the spatial segregation and geopolitical conflicts discussed above). Rather, they are "superimposed upon them", so that "noo-politics commands and reorganizes the other power relations because it operates at the most deterritorialized level." ${ }^{35}$
In other words: in times of mass-communication, the control over a discourse becomes equally as important as, and in fact constituent of, economic, political and territorial power. It is the era of "soft power" in which the logic of coercion has been replaced by the far more subtle logic of persuasion.

\section{Utopia on Life Support}

It is in this context, as instruments of persuasion and noo-politics, that the data center images are to be situated. Because, though it has become obvious that in cyberspace, property and context do matter, subjectivity and identity are not per se free - in short the utopia of the bodiless and emancipatory internet has failed to materialize -, there are powers at work that have every reason to keep this naive optimism of information technology as an "inherently humane, democratizing force in contemporary life" ${ }^{\prime 36}$ alive in public opinion. The images thus are part of the complex life-support system of a failed utopia.

So let us now return to the images themselves. Their soothing symmetry as a means of staging Google as a good caretaker, in perfect control of the stored information, has already been investigated. If we now allow ourselves the aforementioned pars pro toto identification - analyzing the data centre images as images of the internet - what vision of this Internet do the photographs communicate?

First, re-examining the context of the images' release, it might be suggested that the withholding of technical know-how was not the only motivation for the secrecy surrounding the data centers. It was also the reluctance to present the Internet as a physical entity, to disclose the Internet as a "place". It is the same motivation behind Google not representing itself as a physical product: it does not have a star architect designing its headquarters - think Foster's iconic Apple headquarters in Cupertino; nor does it implant its presence into the physical fabric of the city - think the "bold architectural statements" of Bohlin Cywinski Jackson's signature Apple concept stores. ${ }^{37}$

Once forced by public scrutiny to give up this mystifying abstractness, an image of the Internet is conjured up that consists of a number of claims associated with the utopia of the bodiless and moral Internet.

First of all, the Internet is flow, not space. The data center's colorful cables, pipes and ducts echo the aesthetic of the Centre Pompidou but also the words of one of its most fervent advocates:

"When your house contains such a complex of piping, flues, ducts, wires, lights, inlets, outlets, ovens, sinks, refuse disposers, hi-fi re-verberators, antennae, conduits, freezers, heaters -when it contains so many services that the hardware could stand up by itself without any assistance from the house, why have a house to hold it up." 


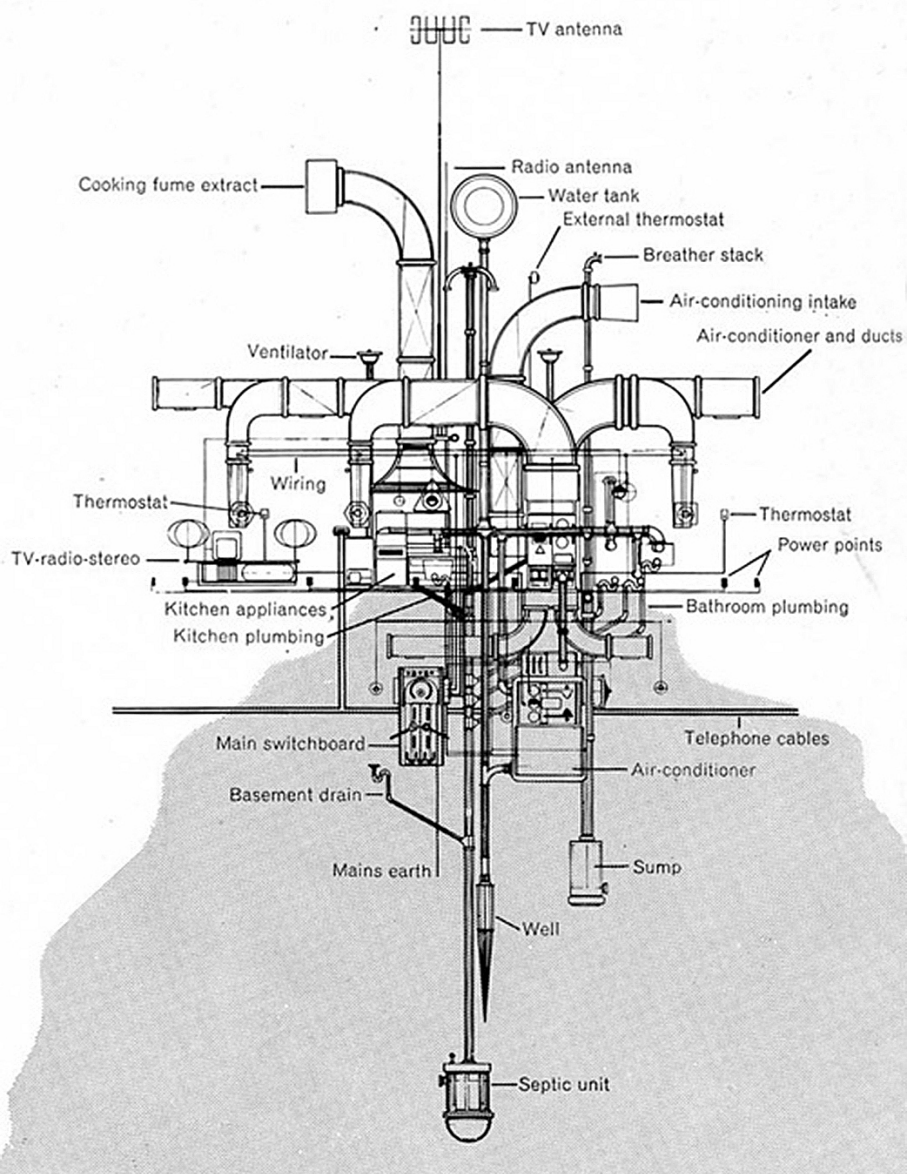

Figure 7: Reyner Banham and Francois Dallegret, Illustration from "a Home is not a House", 1965

In Reyner Banham's vision, the flow emancipates itself from its container - as the mind had emancipated from place in the nineties utopias of the Internet. The pipes in the photographs are to be read as these flows, as arrows (so fetishisized in current architectural representation), as circulation. All is in flux, nothing is fixed - as is the case for the representation of the Googleplex or other Google headquarters, where flexibility, play and changeability are enacted by a creative and colorful chaos of bikes, bean bags, slides, ping pong tables and artificial beaches. Effectively, by outplaying and masking the actual building in the background, they dematerialize its architectural body. The Internet is bodiless.

Also, the Internet is flat, not hierarchic. Shot from a (central) birds-eye perspective, the servers are lined up in the egalitarian and endlessly expandable modules of the industrial warehouse grid. The Internet is democratic.
Finally, the Internet is in nature, not in territory. The data centers are shown, not in the US or in (closely allied) countries like Belgium or Finland, they are not integrated in an urban or infrastructural fabric, with its complex overlapping of interests and inequalities. Their deterritorialized environment is a natural one, in which they thrive symbiotically. Sustainability, the main focus of the images' captions, is also radiated by the images: the data centers yield energy from wind mills and cooling from the ice of the surrounding lake. A herd of deer fearlessly approaches the data center and peacefully grazes on the surrounding grasses.

This last image is an obvious case of digital manipulation and was immediately uncovered as such by online Photoshop forensics. The data center images are carefully crafted utopian constructions.

\section{Projected Machinations}

The recent revival of the data centre images following the aforementioned revelations of mass government surveillance, makes strikingly apparent the momentariness and fallibility of such utopian constructions. Now that anxiety about data storage and privacy has shifted into the foreground of public consciousness, the images have reappeared as decontextualised stock images that illustrate articles on the NSA, PRISM and "the architecture of surveillance". ${ }^{38}$

One image seems to be particularly popular in this context. ${ }^{39}$ The symmetrically composed photograph shows the colourfully lit aisle of a network room in an lowa data centre. At the vanishing point, a person appears. Two layers of plastic curtains separating different thermal zones within the data centres reflect the bright router lamps and, overlaying the reflections upon the figure, turn it into a blurred silhouette. The identity of this silhouette becomes ambivalent: whereas in the original publication context, one would have intuitively identified him as a maintainer, now he becomes an easy target for the viewer's imagination of more ominous machinations.

In short, the reception of the images in question is conditioned by the timely projections of public perception as well as by the original intentionality of its production. The two, of course, stand in mutually interdependency and it is unlikely that, if the photographs were taken today, they would be constructed in quiet the same way. However, the aim of this article has been more to study the mechanisms behind the images' production than to reconstruct their public reception. This production then, must be analyzed within its historical context, a snapshot of a now difficult to grasp pre-Snowden moment of innocent transparency.

\section{Conclusion}

In this article, we have interpreted the Google data centre images published as "Where the internet lives" as symbolic representations of the space of the Internet which act as a life-support system of its failed utopia. Such representations of space are, as Henri Lefebvre has 


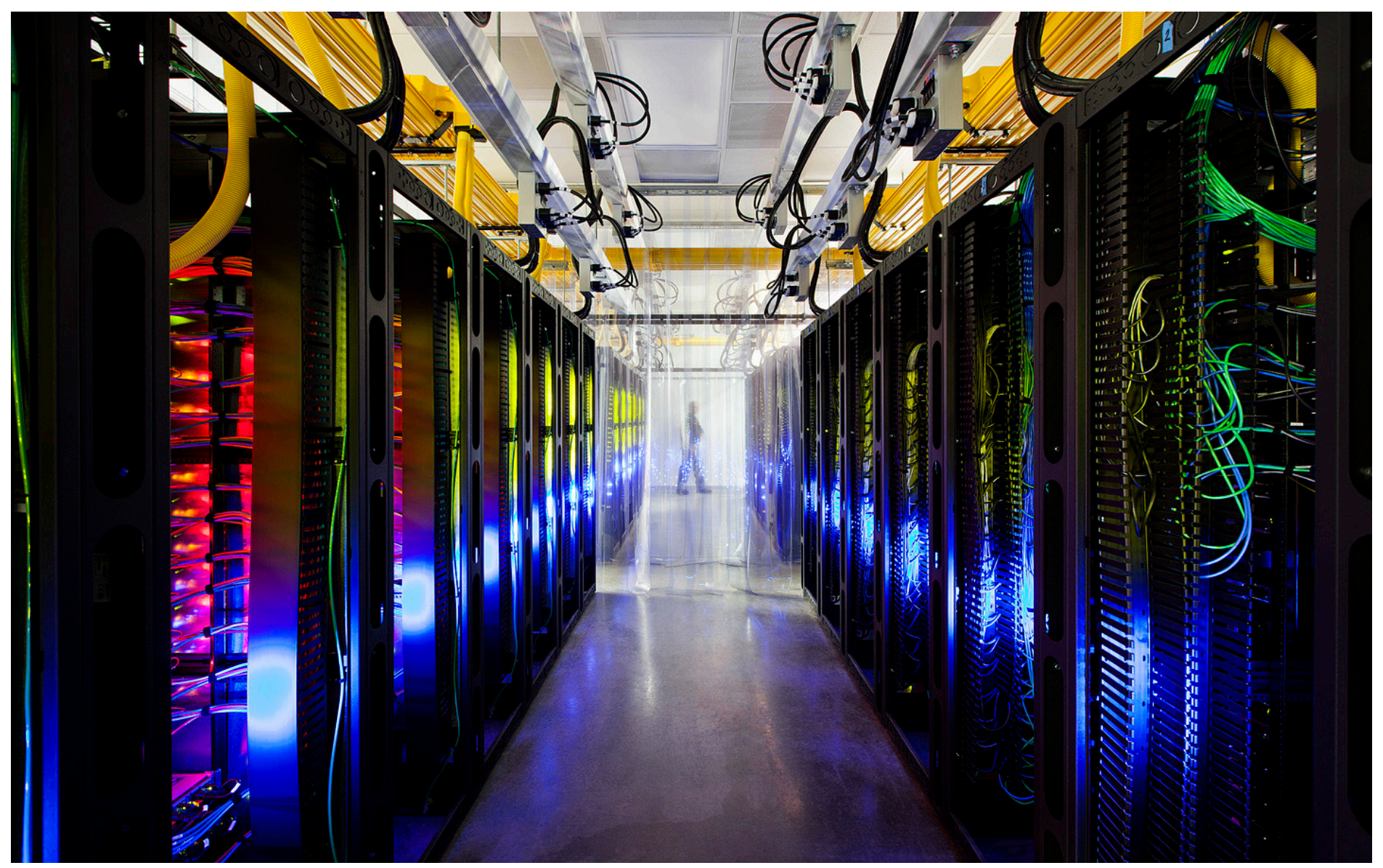

Figure 8: Image from "Where the internet lives", Photographer: Connie Zhou

pointed out, inherently conservative as they "serve to maintain [...] social relations in a state of coexistence and cohesion. It displays them while displacing them - and thus concealing them in symbolic fashion - with the help of, and onto the backdrop of, nature". ${ }^{40}$ The utopia of a bodiless and moral Internet thus sustains existing hegemonies, the success of which depends on "their ability to reveal what is beyond dispute and to hide what ought to be discussed". ${ }^{41}$ We have also pinpointed quite a number of topics "that ought to be discussed" - socio-geographical inequality, corporate interest, interdependencies within the militaryindustrial-informational complex.

The images are instruments of noo-politics as they create a "discursive sphere that allows for the consolidation of merchant power and the continued existence of the military-industrial complex beyond the reach of public scrutiny and possible contestation." Crucial to the creation of this discourse is the "ability to present its own interests as universal and objective." $" 2$
The visual attraction, the aesthetic splendor of the photographs is instrumental in the dissemination of this discourse. Not only does is draw attention in a time of information overload and "Economy of Attention"43. Also, by being complaisant, they make us feel comfortable with the status quo. The images are symbolic universes that are a "means of recognition rather than knowledge" 44 ; they soothe rather than irritate. Hence the title of this essay, quoting the reaction of a blogger to the release of the images: "so it really is a series of tubes".

So what can be gained from this analysis? The message of this article is something of a brainteaser. It describes how technologies extend into our mind only to make us believe they are exterior to it. It unravels techniques of how a medium (the internet) is used to disseminate an image of this same medium mystifying these very techniques.

It is important to unravel these mystifications, to deconstruct our own comfort zones and to understand the interdependencies and multiplicities of the status quo, before formulating a counter-utopia that falls in the same logical traps or adheres the same naive optimism. A model 
exclusively concentrating on providing democratic access to the Internet or on protecting the private informational sphere against commodification would not address political or socio-geographical issues and would fail to acknowledge the interdependencies of the virtual and physical realms that define the Internet.

Likewise, a discourse that presents the Internet as a necessarily liberating or hegemonic force would fail to acknowledge the Internet's multiplicity, deriving from the multiple uses of an amoral medium. A useful model for counter-agency would thus situate itself on the interface between the physical and virtual, at the "intertwining of flows and places" 45 and would use the internet as a tool for change rather than just hailing it as the deliverer of liberation.

\section{Bibliography}

Augé, Marc, Non-places: Introduction to an Anthropology of Supermodernity. London: Verso, 1995.

Berger, John, Ways of Seeing, London: Penguin, 2008.

Edmund Burke, A Philosophical Enquiry into the Origin of our Ideas of the Sublime and Beautiful, London: Routledge, 1958, originally published in 1757.

Castells, Manuel, "Space of Flows, Space of Places." In Rethinking Technology. A Reader in Architectural Theory, edited by William Braham and Jonathan Hale, 450-456. London: Routledge, 2007.

Coupland, Douglas, Microserfs. London: Flamingo, 1995.

Franck, Georg, Mentaler Kapitalismus: Eine politische Ökonomie des Geistes. Wien: Carl Hanser Verlag, 2005.

Halpin, Harry, "The Philosophy of Anonymous. Ontological Politics without Identity," Radical Philosophy 17 (2012): 19-28.

Hozic, Aida, "Uncle Sam Goes to Siliwood: Of Landscapes, Spielberg and Hegemony," Review of International Political Economy 6/3 (Autumn, 1999):289-312.

Lefebvre, Henri, The production of space. Oxford: Blackwell, 1991.

Lazzarato, Maurizio, "Immaterial Labor," in Radical Thought in Italy: A potential politics, ed. Paolo Virno and Michael Hardy (Minneapolis, University of Minnesota Press, 2006) 134-146.

Lazzarato, Maurizio, "The Concepts of Life and the Living in the Societies of Control," in Deleuze and the Social, ed, Martin Fuglsang and Bent Meier Sorensen (Edinburgh: Edinburgh University Press, 2006), 171-190.

May, Christopher, The Information Society: A Sceptical View. Cambridge: Polity Press, 2002.
McLuhan, Marshall and Fiore, Quentin, The Medium is the Massage : an Inventory of Effects, Corte Madera: Gingko, 2001.

Ohlin, Alix. 2002. "Andreas Gursky and the Contemporary Sublime". Art Journal. 61 (4): 23-35.

Von Knöfel, Ulrike "Das mit der Wahrheit ist Quatsch. Interview mit Andreas Gursky and Thomas Ruff," Der Spiegel, March 12, 2012.

Winner, Langdon, "Silicon Valley Mystery House," in Variations on a theme park: the new American city and the end of public space, ed. Michael Sorkin (New York: Hill and Wang, 1992) 30-60.

Wright, Gwendolyn, "The Virtual Architecture of Silicon Valley," Journal of Architectural Education 54/2 (Nov. 2000): 88-94.

\section{Endnotes}

1 Paul Rhode, October 17, 2012, "Where the internet lives," http://www. paulrohde.com/where-the-internet-lives, accessed October 5, 2013. 2 Steven Levy, "Google Throws Open Doors to Its Top-Secret Data Center," Wired, October 17, 2012, accessed October 5, 2013, http:/l www.wired.com/wiredenterprise/2012/10/ff-inside-google-data-center. 3 Google Plus forum users, October 20 to October 24, 2012, accessed January 5, 2013, https://plus.google.com/+google/posts/Gk8ScjPX23n. 4 "Google tries wowing the world with a look at its data centers," Technet Online, October 21, 2012, accessed 10 January 2013, http:// technet-online.com/google-tries-wowing-the-world-with-a-look-at-itsdata-centers.

5 "Where the Internet Lives: The First-Ever Glimpse Inside Google's Data Centers," Colossal, October 17, 2012, accessed October 5, 2013, http://www.thisiscolossal.com/2012/10/where-the-internet-lives-the-firstever-glimpse-inside-googles-data-centers.

6 "Where the internet lives".

7 Cade Metz, "Super-Secret Google Builds Servers in the Dark," Wired, March 15, 2012, accessed October 5, 2013, http://www.wired.com/ wiredenterprise/2012/03/google-miner-helmet/?rm.

8 Alexis Madrigal, "Open Source Design 04: The architecture of Facebook", Domus, June 23, 2011, accessed 5 October, 2013, http:// www.domusweb.it/en/architecture/2011/06/23/open-source-design-04the-architecture-of-facebook.html.

Eric Smalley, "Facebook Seeks Free Love Among Data Center Giants," Wired, 28 October, 2011, accessed 5 October, 2013, http://www.wired. com/wiredenterprise/2011/10/facebook-open_compute/.

Martin Schoeller, "A glimpse inside a Facebook server farm," Time Magazine, accessed 5 October, 2015, http://www.time.com/time/ photogallery/0,29307,2036928,00.html.

9 "Interview: Connie Zhou On Being The First Photographer Inside Google's Massive Data Centers," Pop Photo, accessed October 5, 2013, http://www.popphoto.com/photos/2012/10/interview-connie-zhoubeing-first-photographer-inside-googles-massive-data-centers. 
10 Edmund Burke, A Philosophical Enquiry into the Origin of our Ideas of the Sublime and Beautiful (London: Routledge, 1958), 36.

11 Alix Ohlin, "Andreas Gursky and the Contemporary Sublime," Art Journal 61 (2002): 25.

12 Ulrike Von Knöfel, "Das mit der Wahrheit ixst Quatsch. Interview mit Andreas Gursky and Thomas Ruff," Der Spiegel, March 12, 2012, 143. 13 Peter van de Ploeg, "Google publiceert prachtige foto's van datacentra - maar zijn ze echt?", NRC, October 20, 2012, accessed October 5, 2013, http://www.nrc.nl/nieuws/2012/10/20/googlepubliceert-prachtige-fotos-van-datacentra-maar-zijn-ze-echt-nee/. 14 "Interview: Connie Zhou On Being..."

15 Marshall McLuhan and Quentin Fiore, The Medium is the Massage : an Inventory of Effects (Corte Madera: Gingko, 2001), 53.

16 Although one could of course argue that, in a final act of printing or publishing the photographs and presenting them as art pieces, both effectively objectify and externalize them.

17 John Berger, Ways of Seeing (London: Penguin, 2008), 4. 18 Douglas Coupland, Microserfs (London: Flamingo, 1995), 23. 19 John Perry Barlow, "A Declaration of the Independence of Cyberspace," February 9, 1996, accessed October 5, 2013, https:// projects.eff.org/ barlow/Declaration-Final.html.

20 Harry Halpin, "The Philosophy of Anonymous. Ontological Politics without Identity," Radical Philosophy 17 (2012): 20.

21 Christopher May, The Information Society: A Sceptical View (Cambridge: Polity Press, 2002), quoted by "The Californian Ideology," accessed October 5, 2013, http://en.wikipedia.org/wiki/Californian_ Ideology.

22 Adam Curtis, All Watched Over by Machines of Loving Grace, Documentary (May 23, 2011, BBC2).

23 Brian Doherty, "John Perry Barlow 2.0: The Thomas Jefferson of cyberspace reinvents his body - and his politics", Reason, August/ September, 2004, accessed October 5, 2013, http://reason.com/ archives/2004/08/01/john-perry-barlow-20.

24 Halpin, "The Philosophy of Anonymous," 20.

25 The companies insist on not having cooperated with government by giving them access to their data. Recent revelations indicate that the N.S.A. has obtained direct access to their information by tapping the fiber-optic cables connecting the data centers. Ewen MacAskill et al., "GCHQ taps fibre-optic cables for secret access to world's communications," The Guardian, 21 June, 2013, accessed 19 December, 2013, http://www.theguardian.com/uk/2013/jun/21/gchqcables-secret-world-communications-nsa.

26 Gwendolyn Wright, "The Virtual Architecture of Silicon Valley," Journal of Architectural Education 54/2 (Nov. 2000): 89.

27 Langdon Winner, "Silicon Valley Mystery House," in Variations on a theme park : the new American city and the end of public space, ed. Michael Sorkin (New York: Hill and Wang, 1992) 43.
28 Aida Hozic, "Uncle Sam Goes to Siliwood: Of Landscapes, Spielberg and Hegemony," Review of International Political Economy 6/3 (Autumn, 1999): 301. 29 Quoted from the Council of Economic Advisors by Hozic, "Uncle Sam Goes to Siliwood," 297. 30 "About Gigapan", last modified 5 October, 2013, http://gigapan.com/ cms/about-us.

31 Winner, "Silicon Valley Mystery House," 49.

32 Manuel Castells, "Space of Flows, Space of Places," in Rethinking Technology. A Reader in Architectural Theory, ed. William Braham and Jonathan Hale (London: Routledge, 2007) 450.

33 Maurizio Lazzarato, "Immaterial Labor," in Radical Thought in Italy: A potential politics, ed. Paolo Virno and Michael Hardy (Minneapolis, University of Minnesota Press, 2006) 134.

34 Maurizio Lazzarato, "The Concepts of Life and the Living in the Societies of Control," in Deleuze and the Social, ed, Martin Fuglsang and Bent Meier Sorensen (Edinburgh: Edinburgh University Press, 2006), 197.

35 Lazzarato, "The Concepts of Life," 187.

36 Winner, "Silicon Valley Mystery House," 49.

37 "Apple Store, Fifth Avenue," Bohlin Cywinski Jackson, accessed

December 16, 2013, http://

www.bcj.com/public/projects/project/82.

38 AJ Artemel, "The Architecture of Surveillance," Gizmodo, 18 June, 2013, accessed 19 December, 2013, http://www.gizmodo.com. au/2013/06/the-architecture-of-surveillance.

39 e.g. Nicole Perloth and John Markoff, "N.S.A. May Have Hit Internet Companies at a Weak Spot," The New York Times, 25 November, 2013, accessed 19 December, 2013, http://www.nytimes.com/2013/11/26/ technology/a-peephole-for-the-nsa.

Leo Kelion, "Q\&A: NSA's Prism internet surveillance scheme", BBC News, 1 July, 2013, accessed 19 December, 2013, http://www.bbc. co.uk/news/technology-23051248.

40 Henri Lefebvre, The production of space (Oxford: Blackwell, 1991) 32.

41 Hozic, "Uncle Sam Goes to Siliwood," 304.

42 Hozic, "Uncle Sam Goes to Siliwood," 299-301.

43 Georg Frank, Mentaler Kapitalismus: Eine politische Ökonomie des Geistes (Vienna: Carl Hanser Verlag, 2005) 177. 44 Marc Augé, Non-places: Introduction to an Anthropology of Supermodernity (London: Verso, 1995) 33. 45 Manuel Castells, "Space of Flows," 447. 